\title{
Kearifan Tempatan dalam Kulit Buku Sastera Kanak-kanak Terpilih Terbitan PTS
}

\author{
Local Wisdom of Cover Design in Selected Children's Literature Published by PTS
}

\author{
${ }^{\text {I}}$ Tengku Intan Maslina Tengku Mohd Ali, ${ }^{2}$ Madiawati Mamat@Mustafa, ${ }^{3}$ Rohayati Junaidi \\ ${ }^{1,2}$ Jabatan Kesusasteraan Melayu, Akademi Pengajian Melayu, \\ Universiti Malaya, Kuala Lumpur, Malaysia \\ ${ }^{3}$ Jabatan Bahasa dan Kesusasteraan Melayu, Fakulti Bahasa dan Komunikasi, \\ Universiti Pendidikan Sultan Idris, Tanjong Malim, Perak, Malaysia \\ 'inmarlin@um.edu.my, ${ }^{2}$ atie@um.edu.my, ${ }^{3}$ rohayati@fbk.upsi.edu.my
}

Received: 02 October 2020; Accepted: 29 December 2020; Published: 30 December 2020

To cite this article (APA): Tengku Mohd Ali, T. I. M., Mamat@Mustafa, M., \& Junaidi, R. (2020). Kearifan Tempatan dalam Kulit Buku Sastera Kanak-kanak Terpilih Terbitan PTS. Jurnal Peradaban Melayu, 15, 22-37. https://doi.org/10.37134/peradaban.vol15.3.2020

To link to this article: https://doi.org/10.37134/peradaban.vol15.3.2020

\begin{abstract}
ABSTRAK
Cerita kanak-kanak dalam penerbitan sastera kanak-kanak semakin berkembang pesat seiring dengan perubahan zaman dan kepesatan dunia dalam arus teknologi maklumat. Perkembangan pesat teknologi turut memberi kesan positif terhadap perubahan reka bentuk (design) kulit buku dalam penerbitan sastera kanak-kanak pada masa kini. Reka bentuk kulit buku kanak-kanak dihubungkan dengan konsep kearifan tempatan. Oleh hal yang demikian, makalah ini bertujuan untuk mengkaji sejauh manakah reka bentuk kulit buku sastera kanak-kanak di Malaysia menerapkan ciri-ciri kearifan tempatan? Kearifan tempatan merangkumi adat budaya, agama dan kepercayaan, cara hidup dan ilmu pengetahuan yang menjadi pegangan dari zaman berzaman dan identiti sesebuah masyarakat. Bahan kajian ini menggunakan reka bentuk kulit buku siri Young Aisyah dan Penulis Tunas Super yang diterbitkan oleh PTS Publishing House Sdn. Bhd. Justifikasi pemilihan ini kerana Syarikat PTS antara syarikat yang aktif menerbitkan buku sastera kanak-kanak di Malaysia. Kajian ini menggunakan konsep kearifan tempatan yang dikemukakan oleh Geertz (1973), Hiwasaki et al. (2014), Suraya Sintang, Khadijah Mohd Hambali @ Khambali (2015) dan The Center of Folklore Research (2007). Kaedah yang digunakan dalam kajian ini ialah kaedah perpustakaan dan analisis teks. Dapatan kajian memperlihatkan reka bentuk kulit buku sastera kanak-kanak terbitan Syarikat PTS masih mempunyai ciri-ciri kearifan tempatan walaupun tidak secara keseluruhannya. Kesimpulannya, reka bentuk kulit buku cerita kanak-kanak dapat menjadi medium untuk memperkenalkan dan mengangkat kearifan tempatan yang menjadi identiti dan kemegahan bangsa.
\end{abstract}

Kata kunci: Kearifan tempatan, PTS Publishing House Sdn. Bhd., sastera kanak-kanak, penerbitan sastera kanakkanak.

\section{ABSTRACT}

Children's storytelling in children's literature has grown exponentially with the changing times and worlds of information technology. The rapid development of technology has also had a positive impact on the design of book covers in contemporary children's literature. The children's book design is linked to the concept of local wisdom. Therefore, this paper aims to study the extent to which the design of children's literature in Malaysia incorporates local wisdom features. Local wisdom encompasses cultural custom, religion and belief, way of life and knowledge that have been held by time and the identity of a society. This study material is in the design of Siri Young Aisyah and Penulis Tunas Super published by PTS Publishing House Sdn. Bhd. Justify this selection as the PTS Publication 
is one of the leading companies in publishing children's books in Malaysia. This study uses the concepts of local wisdom presented by Geertz (1973), Hiwasaki et al. (2014), Suraya Sintang, Khadijah Mohd Hambali @ Khambali (2015) and The Center of Folklore Research (2007). The methods used in this study were library methods and text analysis. The findings of the study show that the design of the children's literature of PTS Company publications still has some features of local wisdom, though not entirely. In conclusion, children's storybook cover design can be a medium for introducing and upholding local wisdom that is a national identity and pride.

Keywords: Local wisdom, PTS Publishing House Sdn. Bhd., children's literature, the publication of children's literature

\section{PENGENALAN}

Sastera kanak-kanak merupakan karya yang dihasilkan untuk bacaan kanak-kanak. Peter Hunt (2002, hlm. $3 \& 4)$ mendefinisikan 'children books are different from adults' books. They are written for a different audience, with different skills, different needs and different ways of reading." Dengan kata lain, karya untuk kanak-kanak berbeza dengan karya orang dewasa sama ada dari segi khalayak sasaran, cara penulisan, keperluan dan pembacaan. Arba'ie Sujud, Nurul Azimah Abdull Sedik, Nik Rafidah Nik Muhamad Affendi \& Intan Zahariah Gaisun (2014) menyatakan bahawa kesusasteraan kanak-kanak merupakan genre sastera yang mengungkapkan persoalan tentang dunia kanak-kanak. Hadijah Rahmat (2006, hlm. xv) pula mendefinisikan sastera kanak-kanak adalah untuk anak-kanak yang berada dalam lingkungan 16 tahun ke bawah. Dalam penghasilan sastera untuk kanak-kanak, perkara yang sering diutamakan adalah tema dan persoalan yang digarap dalam karya. Namun, dalam memastikan tujuan penghasilan karya itu sampai kepada kanak-kanak, perkara utama yang memainkan peranan penting adalah kulit buku. Hal ini kerana, kulit buku yang menarik mampu menarik keinginan dan perhatian khalayak untuk mendekati serta mendapatkan sesebuah karya.

Rekaan kulit buku kanak-kanak merangkumi tajuk, grafik, font dan gambar yang dilakar dan dipaparkan di muka depan dan belakang buku. Hanafi Mohd Tahir (2016); Hanafi Mohd Tahir, Normah Mustaffa \& Wan Amizah Wan Mahmud (2018) menyatakan bahawa rekaan kulit buku memainkan peranan penting untuk memberi kefahaman awal kepada pembaca. Smith (2019) turut menyatakan rekaan kulit buku dapat menarik minat pembaca untuk mendapatkan buku tersebut. Hal ini menjelaskan bahawa penghasilan rekaan kulit buku kanak-kanak menjadi perkara penting yang harus diambil berat oleh penulis, pereka grafik dan penerbit buku cerita kanak-kanak.

Selain itu, rekaan kulit buku kanak-kanak bukan sahaja mampu menarik minat kanak-kanak, tetapi turut memainkan peranan penting dalam memelihara dan memulihara khazanah bangsa. Unsur kearifan tempatan dapat diterapkan dalam kulit buku kanak-kanak untuk memberi pengetahuan kepada kanakkanak mengenai khazanah bangsa. Kearifan tempatan ialah unsur tradisional, budaya, agama dan merangkumi unsur kebendaan serta intelektualisme yang melambangkan keagungan sesebuah bangsa di dunia.

Berdasarkan buku cerita kanak-kanak yang diterbitkan oleh PTS Publishing House Sdn. Bhd. kajian memfokuskan kepada penghasilan kulit buku cerita kanak-kanak dengan melihat kearifan tempatan yang ditonjolkan dalam karya. Kajian ini menjelaskan sejauh mana kulit buku cerita kanak-kanak yang diterbitkan oleh PTS Publishing House Sdn. Bhd. mengaplikasikan unsur-unsur kearifan tempatan dalam karya terbitan mereka. 


\section{SOROTAN LITERATUR}

Sorotan literatur dalam makalah ini menganalisis literatur terdahulu sama ada di dalam atau di luar negara tentang kearifan tempatan dalam penghasilan kulit buku kanak-kanak. Kajian-kajian yang menunjukkan kepentingan kulit buku dalam menarik minat pembaca dapat dilihat dalam kajian Hanafi Mohd Tahir (2016), Hanafi Mohd Tahir, Normah Mustaffa \& Wan Amizah Wan Mahmud (2019), Christine (1999), Wilson \& Gibb (2014) \& Smith (2019). Kajian yang dilakukan oleh Hanafi Mohd Tahir (2016) yang bertajuk "Kemudahbacaan dan kebolehbacaan tipografi dan visual terhadap reka bentuk kulit buku" yang diterbitkan dalam Jurnal Seni dan Budaya oleh Universiti Teknologi Mara Cawangan Perak, Malaysia menjelaskan bahawa penggunaan dan pemilihan visual yang baik dapat membantu pembaca untuk memahami cerita, mesej dan maksud yang hendak disampaikan dalam sesebuah cerita. Hanafi turut menjelaskan bahawa reka bentuk kulit buku bertujuan untuk menghuraikan dan merumuskan isi kandungan dalam sesebuah cerita. Kulit buku yang baik dapat berperanan mempengaruhi khalayak yang menjadi sasaran.

Seterusnya, Hanafi Mohd Tahir et al. (2018) dalam artikel yang bertajuk "Peranan visual reka bentuk kulit buku terhadap kemudahbacaan khalayak" yang diterbitkan dalam Jurnal Komunikasi, Universiti Putra Malaysia menunjukkan bahawa rekaan kulit buku memainkan peranan penting dalam menyampaikan informasi dan maklumat awal kepada khalayak pembaca sebelum meneruskan pembacaan terhadap sesebuah karya sekali gus dapat menyampaikan maklumat dengan baik kepada pembaca. Hanafi et al. menjelaskan bahawa fotografi pada reka bentuk kulit buku memberi kesan yang lebih baik kepada kemudahbacaan khalayak berbanding ilustrasi.

Christine Suharto Cenadi (1999) dalam kajian yang bertajuk "Elemen-elemen dalam desain komunikasi visual" yang diterbitkan dalam Jurnal NIRMANA, Universitas Kristen Petra, Surabaya menjelaskan bahawa elemen-elemen yang digunakan dalam komunikasi visual, iaitu tipografi, simbolisme, ilustrasi dan fotografi. Dapatan menunjukkan ilustrasi banyak digunakan dalam cerita kanak-kanak dan bertujuan untuk merangsang imaginasi kanak-kanak apabila melihat buku cerita. Smith, J.D. (2019) dalam kajian yang bertajuk "The important of cover design" yang dikeluarkan dalam Writers \& Artists: The insider guide to the media, London, Bloomsbury Publishing menyatakan bahawa kulit buku penting dalam dunia jualan buku yang berdaya saing. Kulit buku menjadi perkara utama yang dilihat oleh pembaca sebelum melihat isi kandungan buku tersebut. Dengan melalui kulit buku, seseorang penulis buku juga dapat dikenali berdasarkan font, gaya penutup, komposisi dan rupa siri yang terdapat pada kulit buku. Penghasilan kulit buku yang baik dapat menarik minat pembaca untuk mendapatkan buku tersebut. Wilson, R., Landoni, M. \& Gibb, F. (2014) dalam kajian yang bertajuk "Guidelines for designing electronic books" dari University of Strathclyde, United Kingdom menjelaskan reka bentuk pada skrin harus dikekalkan dan medium elektronik boleh dieksploitasikan dengan baik. Secara ringkasnya, berdasarkan kajian-kajian lepas yang telah dilakukan oleh pengkaji-pengkaji tempatan dan Barat menunjukkan peranan besar yang digalas oleh reka bentuk kulit buku dalam menarik minat para pembaca untuk mendapatkan sesebuah buku.

Namun begitu belum ada kajian khas yang memfokuskan peranan kulit buku sebagai saluran memperlihatkan kearifan tempatan di mana buku tersebut dihasilkan sekali gus berperanan sebagai identiti negara. Justeru, kajian reka bentuk kulit buku kanak-kanak berlandaskan kearifan tempatan dapat memenuhi ruang dan lompang yang ada bagi melengkapkan dan menyediakan satu penulisan aspek kearifan tempatan dalam reka bentuk kulit buku kanak-kanak. Kesimpulannya, kajian literatur menunjukkan bahawa kulit buku berperanan penting untuk memberi kefahaman awal kepada khalayak sekali gus mampu mempengaruhi khalayak untuk mendapatkan buku tersebut. Oleh hal yang demikian, unsur-unsur tempatan yang melambangkan kesopanan dan identiti bangsa dapat diilustrasikan pada kulit buku sebagai daya penarik sekali gus menjadi medium memperlihatkan kearifan tempatan. 


\section{PERNYATAAN MASALAH}

Reka bentuk kulit buku memberi kesan yang besar dalam mempengaruhi khalayak pembaca untuk tertarik kepada sesebuah buku. Namun kesedaran terhadap kepentingan tersebut masih berada pada tahap yang kurang memuaskan di Malaysia. Pereka grafik bebas Mohd Rasydan Fitri Mohd Baharin berkata dalam Berita Harian "proses penghasilan kulit buku tidak begitu mendapat pengiktirafan berbanding di luar negara mungkin kerana dirasakan tidak begitu penting" (Siti Haliza Yusop, 2017). Smith (2019) menyatakan bahawa "Many writers now take seriously the need to package and market their books professionally, and pro covers are no longer considered 'nice to have'; they are considered essential in the ever more competitive world of book selling." Dengan kata lain, kulit buku memainkan peranan penting dalam dunia penerbitan buku bagi tujuan komersial.

Namun, di Malaysia reka bentuk kulit buku kurang mendapat perhatian yang sewajarnya apatah lagi menitikberatkan aspek-aspek kearifan tempatan dalam rekaan kulit buku. Aspek reka bentuk kulit buku menjadi isu penting dalam menarik perhatian khalayak pembaca untuk mendapatkan sesebuah buku. Oleh itu, seperti mana, karya tempatan yang sarat dengan nilai-nilai tempatan, maka reka bentuk yang digunakan sebagai daya penarik perlu berasaskan budaya dan nilai-nilai tempatan. Kearifan tempatan yang menjadi identiti bangsa Malaysia mampu menjadi daya penarik, memberi kefahaman kepada khalayak tentang keunikan Malaysia dan menjadi identiti karya tempatan. Justeru, berdasarkan permasalahan tersebut, kajian ini amat relevan dilakukan bagi memperlihatkan kepentingan kulit buku sebagai daya penarik yang membawa nilai-nilai tempatan sebagai ciri penting dan identiti bangsa dalam rekaan kulit buku di Malaysia.

\section{OBJEKTIF KAJIAN}

Objektif kajian ini adalah untuk mengkaji sejauh manakah reka bentuk kulit buku sastera kanak-kanak di Malaysia menerapkan ciri-ciri kearifan tempatan dengan menggunakan konsep kearifan tempatan yang dikemukakan oleh Geertz (1973), Hiwasaki et al. (2014), Suraya Sintang, Khadijah Mohd Hambali @ Khambali (2015) dan The Center of Folklore Research (2007).

\section{TEKS KAJIAN}

Kajian ini menggunakan sebanyak 10 buah novel kanak-kanak terbitan PTS Publishing House Sdn. Bhd, iaitu P.A. Eksklusif karya Nur Afiqah (2016), Cik Diva Menari di London karya Nur Alia Irdina (2017), Persahabatan Dunia Ratu Berlian karya Nur Nabihah (2017), Ayahku Superhero karya Rasmawati (2017), Sukan karya Rasmawati (2016) dan empat buah karya Sarimah Hamid dan Reja seperti Siri Young Aisyah: Hari Kantin (2019), Siri Young Aisyah: Juara Kampung Badak Berendam (2019), Siri Young Aisyah: Cuti Sekolah (2019) dan Siri Young Aisyah: Sayang Cikgu (2019).

Justifikasi pemilihan ini kerana PTS Publishing House Sdn. Bhd. merupakan antara syarikat penerbitan yang aktif menerbitkan buku sastera kanak-kanak di Malaysia di samping Siri Young Aisyah dan Penulis Tunas Super adalah siri yang menjadi kegemaran kanak-kanak di Malaysia. Dalam menarik perhatian pembaca untuk mendapatkan sesebuah karya, reka bentuk kulit buku memainkan peranan penting. Oleh hal yang demikian, sebagai sebuah syarikat penerbitan yang aktif menerbitkan buku kanak-kanak, beberapa Siri Young Aisyah dan Penulis Tunas Super terbitan PTS Publishing House Sdn. Bhd. dijadikan teks kajian kerana menampilkan reka bentuk kulit buku yang menarik dan bermakna. Seperti mana, teks cerita yang dihasilkan penulis tempatan membawa mesej dan nilai-nilai tempatan, reka bentuk kulit buku 
turut menggalas konsep yang sama. Hal ini demikian kerana, penghasilan sesebuah reka bentuk kulit buku memberi sinopsis dan gambaran awal kepada isi sesebuah karya.

\section{METODOLOGI KAJIAN}

Kajian ini menggunakan kaedah kualitatif yang merangkumi kaedah perpustakaan dan kaedah analisis teks dengan menggunakan konsep kearifan tempatan yang dikemukakan oleh Geertz (1973), Hiwasaki et al. (2014), Suraya Sintang, Khadijah Mohd Hambali @ Khambali (2015) dan The Center of Folklore Research (2007). Kajian perpustakaan melibatkan pembacaan dan pengumpulan bahan atau sumber yang berkaitan, iaitu tentang kearifan tempatan dalam penerbitan buku kanak-kanak. Sumber utama yang digunakan terdapat dalam bentuk bertulis seperti koleksi persidangan, jurnal-jurnal, latihan ilmiah, kajian sarjana dan tesis yang telah dihasilkan sarjana tempatan dan juga sarjana barat. Kaedah analisis teks melibatkan pemilihan kulit buku cerita kanak-kanak yang memaparkan kearifan tempatan yang diterbitkan oleh PTS Publishing House Sdn. Bhd. Ilustrasi yang digunakan di kulit buku dianalisis dengan menggunakan konsep kearifan tempatan yang dikemukakan oleh Geertz (1973), Hiwasaki et al. (2014), Suraya Sintang, Khadijah Mohd Hambali @ Khambali (2015) dan The Center of Folklore Research (2007). Konsep kearifan tempatan yang digunakan untuk menganalisis kulit buku merangkumi gambaran masyarakat yang meliputi nilai, cara hidup, agama dan ilmu pengetahuan yang menjadi identiti masyarakat Melayu.

\section{KONSEP KEARIFAN TEMPATAN}

Kearifan tempatan adalah pengetahuan yang terkumpul dalam amalan komuniti di sesebuah kawasan. Namun, tidak dinafikan sesebuah kawasan itu memiliki perbezaan dari segi etnik, sosial, aset budaya dan latar belakang sejarah (Yin, 2003 dlm. Mohd Jirey Kumalah, Gusni Saat, Jabil Mapjabil, Rosazman Hussin, Teuku Afrizal \& Mustapa Abu Talip, 2015, hlm. 117). Kearifan tempatan dalam bahasa asing didefinisikan sebagai local wisdom (kebijaksanaan tempatan), local knowledge (pengetahuan tempatan) atau local genius (kecerdasan tempatan). Kearifan tempatan menjadi jambatan yang menghubungkan masa lalu dan sekarang, iaitu generasi nenek moyang dan generasi sekarang sekali gus untuk mempersiapkan generasi masa depan.

Suraya Sintang, Khadijah Mohd Hambali @ Khambali (2015, hlm. 94) menjelaskan kearifan tempatan merupakan khazanah bangsa yang menggambarkan citra, tradisi dan identiti sebenar kekuatan semangat sesebuah bangsa yang besar dan hebat. Kearifan tempatan dianggap sebagai satu cabang ilmu kerana dibina daripada pengalaman sebenar yang dialami dalam waktu yang panjang dan berakar budaya tempatan dan umumnya diterapkan ke dalam amalan masyarakat. Kearifan tempatan tidak hanya bersifat kebendaan tetapi juga melakarkan kearifan yang bersifat intelektualisme dan nilai budaya yang berupaya mendepani pelbagai kerencaman masyarakat.

Geertz (1973) dalam Norhayati Ab. Rahman (2015, hlm. 139) menyatakan kearifan tempatan, iaitu peraturan tidak bertulis dan menjadi acuan masyarakat meliputi seluruh aspek kehidupan yang berhubung dengan peraturan hubungan sesama manusia, peraturan hubungan antara manusia dengan alam dan peraturan hubungan antara manusia dengan ghaib seperti Tuhan, roh dan seumpamanya. Alhafizh Mahardika (2017, hlm. 17) yang memetik Geertz (1973) menyatakan bahawa kearifan tempatan merupakan unsur budaya tradisional yang berakar pada kehidupan masyarakat dan terkait dengan sumber daya manusia, sumber budaya, ekonomi, keamanan dan hukum. Geertz turut berpandangan bahawa kearifan tempatan dapat dilihat sebagai tradisi yang berhubungan dengan kegiatan bertani, penternakan, pembangunan rumah dan lain-lain. 
The Center of Folklore Research (2007) mendefinisikan kearifan tempatan seperti berikut:

1) Local wisdom is an abstract and is related to religion (kebijaksanaan tempatan adalah abstrak dan berkaitan dengan agama)

2) Local wisdom is the potential that protects the community (kebijaksanaan tempatan adalah potensi yang melindungi masyarakat)

3) Local wisdom is the body of knowledge (kebijaksanaan tempatan adalah badan pengetahuan)

4) Local wisdom is an intellectual capital (kebijaksanaan tempatan adalah modal intelektual)

Menurut Hiwasaki et al. (2014), aspek kearifan tempatan adalah pelbagai bentuk, antaranya cerita rakyat, lagu, peribahasa, nilai budaya, kepercayaan, ritual, undang-undang adat, bahasa dan amalan pertanian (Mohd Jirey Kumalah et al., 2015, hlm. 117). Dengan kata lain, seni, kebudayaan dan cara hidup yang menjadi pegangan masyarakat sejak zaman berzaman dan menjadi identiti sesebuah masyarakat merupakan kearifan tempatan.

Satu konsep kearifan tempatan tidak mampu menggambarkan ilustrasi kulit buku yang memfokuskan kearifan tempatan secara lebih spesifik dan menyeluruh. Justeru, keempat-empat konsep kearifan tempatan yang diutarakan oleh Geertz (1973), Hiwasaki et al. (2014), Suraya Sintang, Khadijah Mohd Hambali @ Khambali (2015) dan The Center of Folklore Research (2007) diaplikasikan dalam kajian ini. Keempat-empat konsep tersebut dapat menjelaskan gambaran masyarakat merangkumi cara hidup, nilai, budaya dan agama dengan lebih menyeluruh. Kesimpulannya, kearifan tempatan merupakan unsur tradisional yang menggambarkan identiti dan kekuatan sesebuah bangsa yang merangkumi bukan sahaja dalam bentuk kebendaan tetapi juga intelektualisme, budaya, agama dan cara hidup yang diwarisi daripada generasi terdahulu. Kearifan tempatan terbentuk daripada pengalaman sebenar yang berakar budaya tempatan dan menjadi amalan masyarakat. Kearifan tempatan dalam kulit buku cerita kanak-kanak dianalisis berdasarkan paparan reka bentuk kulit buku yang digunakan oleh pelukis dengan melihat unsurunsur kearifan tempatan yang ditonjolkan.

\section{KEARIFAN TEMPATAN DALAM KULIT BUKU KANAK-KANAK TERPILIH TERBITAN PTS}

Reka bentuk kulit buku merupakan aspek penting dalam menarik minat khalayak pembaca untuk mendapatkan bahan bacaan. Smith (2019) menyatakan bahawa reka bentuk kulit buku merupakan perkara pertama yang dapat menarik khalayak mendapatkan sesebuah karya. Hal ini menjelaskan bahawa kekuatan peranan yang dimainkan oleh kulit buku dalam menyampaikan dan menjadi tarikan kepada pembaca. Oleh hal yang demikian, penerapan kearifan tempatan dalam kulit buku cerita kanak-kanak dapat menjadi satu langkah penting bagi memperkenalkan dan mengangkat kearifan tempatan kepada generasi muda. Hal ini kerana kekuatan sesebuah bangsa di dunia terletak pada kearifan tempatan yang menjadi citra dan identiti bangsa.

Terdapat beberapa aspek yang akan dianalisis untuk meneliti peranan yang dimainkan kulit buku dalam mengangkat kearifan tempatan. Antara aspek yang dianalisis untuk melihat kearifan tempatan dalam kulit buku, iaitu gambaran masyarakat yang ditonjolkan, agama Islam identiti masyarakat Melayu di Malaysia, keakraban masyarakat dengan alam dan gambaran pekerjaan masyarakat. 


\section{GAMBARAN MASYARAKAT MALAYSIA DALAM KULIT BUKU CERITA KANAK- KANAK}

Amalan komuniti sesebuah masyarakat merupakan salah satu aspek kearifan tempatan yang boleh dilihat dalam reka bentuk kulit buku cerita kanak-kanak. Kearifan tempatan menggambarkan citra, tradisi dan identiti sebenar kekuatan semangat sesebuah bangsa yang besar dan hebat. Oleh hal yang demikian, kekuatan sesebuah bangsa dapat dilihat dalam reka bentuk kulit buku cerita kanak-kanak yang terpilih melalui penerapan aspek agama, hubungan dengan alam ghaib, mengangkat watak-watak legenda yang menjadi identiti bangsa dan keunikan sesebuah tempat.

Berdasarkan siri Young Aisyah dan Penulis Tunas Super memperlihatkan watak kanak-kanak perempuan yang dilukis menggunakan tudung kepala. Penonjolan watak kanak-kanak perempuan yang bertudung ini memperlihatkan gambaran identiti masyarakat Malaysia yang diiktiraf dunia sebagai negara Islam. Perkara ini telah termaktub dalam Perlembagaan Perkara 160 yang menetapkan agama Islam sebagai agama rasmi negara. Suraya Sintang, Khadijah Mohd Hambali @ Khambali (2015, hlm. 94) menjelaskan kearifan tempatan merupakan khazanah bangsa yang menggambarkan citra, tradisi dan identiti sebenar kekuatan semangat sesebuah bangsa yang besar dan hebat. Jelaslah, penonjolan watak bertudung dalam rekaan kulit buku cerita kanak-kanak menggambarkan identiti sebenar masyarakat Malaysia yang dikenali dunia sebagai negara Islam.

Di samping itu, terdapat juga kulit buku cerita kanak-kanak yang memperlihatkan tarian tradisional yang menjadi identiti bangsa Melayu yang kaya dengan seni budaya. Contohnya, dalam kulit buku cerita kanakkanak yang bertajuk Cik Diva Menari di London memperlihatkan watak seorang kanak-kanak yang menggunakan baju kurung dan bertudung serta disesuaikan dengan cermin mata hitam berdiri di tengah kota London yang didiami oleh majoriti penduduk bukan beragama Islam untuk melakukan persembahan tarian tradisional. Bangsa Melayu terkenal dengan seni tarian yang lemah-gemalai, tetapi penuh dengan kesopanan seperti zapin, endang, tarian piring, dan tarian asyik. Mohammad Yassin Ahmad (2000) dalam Lawrence Dino (2007), menyatakan bahawa seni tari Melayu amat rapat dengan pengaruh luar seperti kesenian Arab dan Sepanyol, namun asas tarian tetap bersifat seni Melayu. Tarian Melayu yang kerap dipersembahkan ialah joget, zapin, inang dan ronggeng. Berdasarkan pernyataan tersebut memperlihatkan bahawa seni tarian tradisional Melayu telah lama wujud dan menjadi sebati dalam kehidupan masyarakat Melayu yang menjadi warisan dan identiti bangsa Melayu. Secara tidak langsung, paparan tarian tradisional yang menjadi identiti bangsa Melayu telah ditonjolkan dalam kulit buku cerita kanak-kanak mampu menjadi medium untuk memperlihatkan kearifan tempatan dari segi seni tari. Hiwasaki et al. (2014) menyatakan bahawa seni termasuk dalam kearifan tempatan yang menjadi identiti sesebuah masyarakat.

Reka bentuk kulit buku yang memperlihatkan seni tari yang menjadi identiti bangsa Melayu dapat dilihat dalam Gambar 1. 


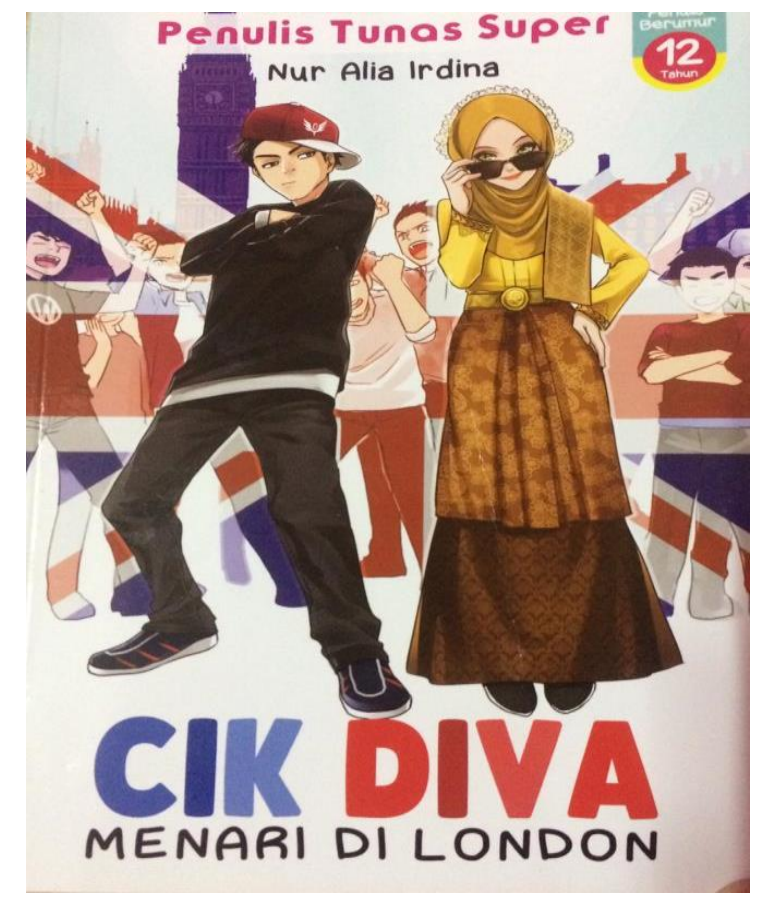

Gambar 1 Cik Diva Menari di London (2017).

Selain itu, buku cerita kanak-kanak yang bertajuk Persahabatan Dunia Ratu Berlian (2017) memperlihatkan pelukisan dua orang watak kanak-kanak yang mengangkat tema persahabatan manusia dengan makhluk dari alam lain. Lukisan reka bentuk kulit buku cerita kanak-kanak yang mengangkat cerita persahabatan dengan makhluk alam ghaib merupakan salah satu kearifan tempatan yang terdapat pada bangsa Melayu. Hal ini dapat dilihat sebelum kedatangan agama Islam, masyarakat Melayu terkenal dengan kepercayaan animisme yang mempercayai kewujudan penunggu atau puaka, hantu, polong, orang bunian atau pontianak yang menghuni sesuatu daerah atau tempat tertentu (Pengeran Mohd Pengeran Abd Rahman, 1992, hlm. 19).

Reka bentuk kulit buku yang memperlihatkan kepercayaan animisme yang pernah menjadi kepercayaan masyarakat Melayu sebelum kedatangan Islam dapat dilihat dalam Gambar 2.

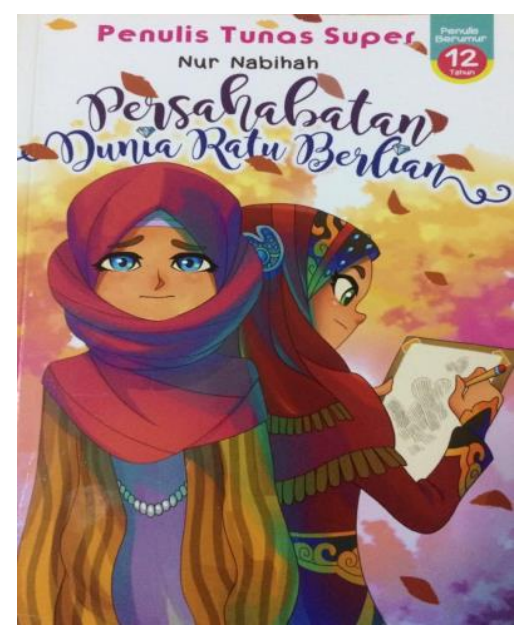

Gambar 2 Persahabatan Dunia Ratu Berlian (2017). 
Ringkasnya, penerapan kearifan tempatan dalam kulit buku cerita kanak-kanak dapat dilihat dalam siri Young Aisyah dan Penulis Tunas Super yang menggambarkan identiti dan kekuatan masyarakat Malaysia. Reka bentuk kulit buku cerita kanak-kanak yang memperlihatkan watak bertudung, tarian tradisional, aspek animisme dan keperwiraan menunjukkan ciri-ciri kearifan tempatan yang memberi gambaran masyarakat Melayu di Malaysia.

\section{AGAMA ISLAM MENJADI IDENTITI MASYARAKAT MELAYU MALAYSIA DALAM KULIT BUKU CERITA KANAK-KANAK}

Geertz (1973) menyatakan kearifan tempatan meliputi seluruh aspek kehidupan berkaitan peraturan sesama manusia, alam dan Maha Pencipta. Ratna (2014, hlm. 186) menyifatkan kearifan lokal merupakan berbagai bentuk kebijaksanaan yang terdapat di wilayah tertentu dan digunakan secara turun-temurun sebagai salah satu sarana penunjang untuk mewujudkan stabiliti sosial masyarakat. Perkara ini menjelaskan bahawa kearifan tempatan merupakan salah satu aspek penting dalam memperkuatkan generasi muda. Penanaman nilai kearifan tempatan dalam kulit buku cerita kanak-kanak dapat dilihat dalam penerapan nilai-nilai baik yang melambangkan masyarakat Melayu Islam.

Masyarakat Melayu terkenal dengan sifat lemah-lembut dan sopan santun. Kesopanan bermaksud menjaga kelakuan supaya tidak bertentangan dengan budaya tempatan dan melanggar syariat agama. Dalam kulit buku cerita kanak-kanak yang dianalisis memperlihatkan nilai-nilai kesopanan yang mewakili budaya masyarakat Melayu. Hal ini dapat dilihat melalui siri Young Aishah dan Penulis Tunas Super yang memperlihatkan watak kanak-kanak yang dilukiskan menunjukkan ciri-ciri budaya Melayu yang menampilkan nilai kesopanan. Nilai lemah lembut dan kesopanan ini dapat dikaitkan dengan pelukisan watak kanak-kanak perempuan dan watak kanak-kanak lelaki memperlihatkan batas-batas kesopanan dan tidak bersentuhan.

Selain itu, terdapat juga nilai agama yang dipaparkan dalam kulit buku yang memperlihatkan kearifan tempatan yang tidak lari dari nilai-nilai agama. Agama Islam merupakan agama yang dianut oleh masyarakat Melayu sekali gus menjadi pegangan dan pembimbing dalam kehidupan. Berdasarkan kulit buku cerita kanak-kanak terpilih memperlihatkan lakaran watak perempuan bertudung yang menggambarkan masyarakat Melayu Islam. Contohnya, dalam kulit buku cerita yang bertajuk P.A. Eksklusif menampilkan watak perempuan yang bertudung meskipun berada di tengah bandar yang serba moden. Hal yang sama turut dapat dilihat dalam Cik Diva Menari di London yang memperlihatkan watak perempuan bertudung yang berada di tengah kota London dan dikelilingi oleh orang lelaki. Rekaan kulit buku cerita kanak-kanak tersebut menjelaskan bahawa keagungan agama Islam yang menjadi identiti bangsa Melayu. Penyebaran agama Islam ke Tanah Melayu telah berlaku kira-kira seribu tahun yang lalu, iaitu sejak awal penubuhan kerajaan Melaka di bawah pimpinan Parameswara. Shaharuddin Pangilun \& Farhah Zaidar Mohamed Ramli (2017, hlm. 144) menyatakan bahawa tindakan Parameswara menganut agama Islam pada tahun 1414 Masihi dengan gelaran Megat Iskandar Shah telah merancakkan perkembangan Islam di Nusantara dan meletakkan Melaka sebagai pusat penyebaran Islam di rantau ini. Badlihisham Mohd Nasir (2012) menyatakan bahawa penyebaran agama Islam di Tanah Melayu dibuktikan dengan penemuan Batu Bersurat di Kuala Berang, Terengganu yang menyatakan kedatangan Islam sejak 1303. Mohamed Anwar Omar Din (2011) turut menyatakan bahawa pada abad ke-15, Kesultanan Melayu Melaka pernah menjadi pusat penyebaran Islam. Secara ringkasnya, reka bentuk kulit buku cerita tersebut menjelaskan bahawa meskipun berada di tempat yang berbeza dengan budaya, namun adat, agama dan budaya masih dikekalkan sebagai melambangkan identiti bangsa yang harus dipelihara.

Reka bentuk kulit buku yang memperlihatkan keagungan agama Islam sebagai citra bangsa Melayu Islam dapat dilihat dalam Gambar 3. 
Berdasarkan Gambar 3 memperlihatkan watak perempuan yang menggenakan pemakaian yang sopan dan bertudung kepala sebagai lambang wanita Islam yang menutup aurat. Perkara ini secara tidak langsung memperlihatkan identiti bangsa Melayu Islam. Masyarakat Melayu dengan agama Islam adalah dua perkara yang bergerak selari. Menurut Perkara 160 (2) Perlembagaan Malaysia menyatakan bahawa orang Melayu itu mestilah beragama Islam. Oleh hal yang demikian, dalam memperkatakan orang Melayu, agama Islam akan turut dilihat sekali. The Center of Folklore Research (2007) mendefinisikan kearifan tempatan seperti berikut; "Local wisdom is an abstract and is related to religion". Dengan kata lain kebijaksanaan tempatan berkait rapat dengan agama dan kepercayaan.

Selain itu, masyarakat Melayu Islam adalah sebuah masyarakat yang terkenal dengan nilai kasih sayang. Kasih sayang sesama insan yang menjadi identiti masyarakat Melayu Islam. Reka bentuk kulit buku yang memperlihatkan masyarakat Melayu Islam yang terkenal dengan nilai kasih sayang dapat dilihat dalam Gambar 4.

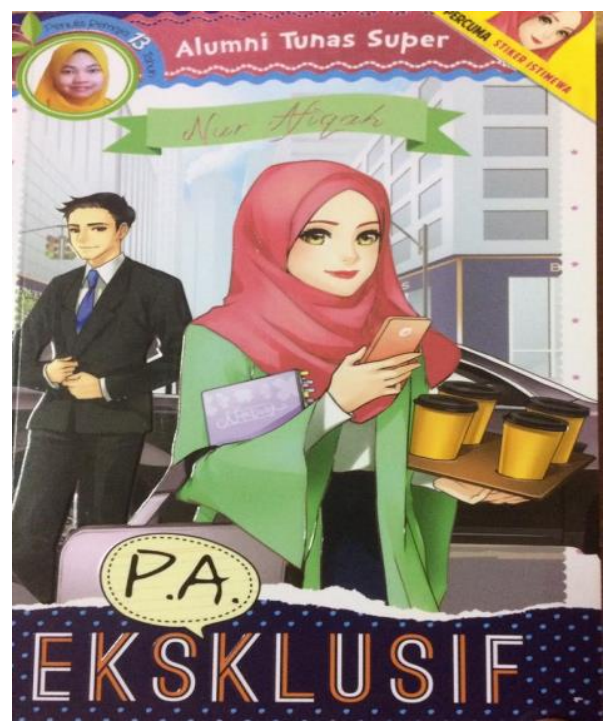

Gambar 3 P.A Eksklusif (2016). 


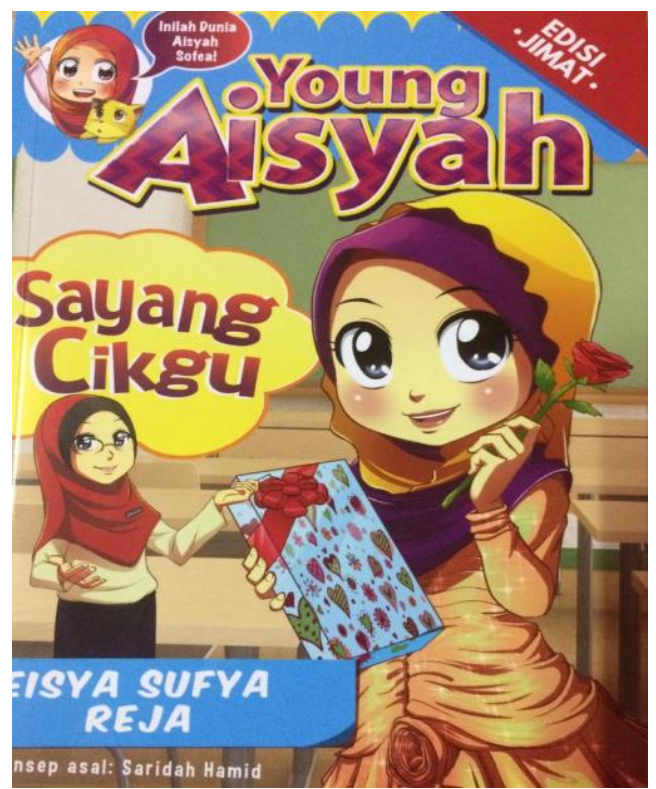

Gambar 4 Young Aisyah: Sayang Cikgu (2019).

Kulit buku cerita kanak-kanak yang dianalisis memperlihatkan nilai kasih sayang yang menjadi salah satu aspek penting dalam reka bentuk kulit buku yang menerapkan kearifan tempatan masyarakat. Contohnya, kulit buku cerita kanak-kanak yang bertajuk Ayahku Superhero, siri Young Aisyah: Sayang Cikgu, Persahabatan Dunia Ratu Berlian dan Puteri Berlian menjadi lambang identiti masyarakat Melayu Islam yang dikenali sebagai masyarakat penyayang. Ilustrasi kulit buku yang memperlihatkan watak kanakkanak memegang hadiah dan sekuntum bunga dalam Siri Young Aisyah: Sayang Cikgu memperlihatkan hubungan kasih sayang antara kanak-kanak dengan guru. Hal ini kerana cerita tersebut mengisahkan penghargaan kanak-kanak-kanak kepada guru sempena Hari Guru. Sementara itu, Ayahku Superhero memperlihatkan cerita yang mengisahkan pengorbanan dan kasih sayang antara ayah dengan anak yang diterjemahkn melalui kekuatan fizikal dan mental watak ayah. Persahabatan Dunia Ratu Berlian dan Puteri Berlian mengisahkan kisah persahabatan kanak-kanak dengan rakan. Geertz (1973) menyatakan kearifan tempatan meliputi seluruh aspek kehidupan yang berhubung dengan peraturan hubungan sesama manusia. Perkara ini selari dengan pernyataan Siti Norlina Muhamad, Ahmad Kilani Mohamed, Zulkifli Haron \& Siti Aisyah Abdul Rahman (2004) menyatakan bahawa agama Islam sangat menekankan usaha mewujudkan masyarakat penyayang dan konsep masyarakat penyayang yang digariskan dalam Islam, iaitu hubungan erat manusia dengan Allah, hubungan manusia sesama manusia dan hubungan manusia dengan alam sejagat. Petikan berikut memperlihatkan sifat yang menjadi identiti masyarakat Malaysia.

"Sifat "ikram" dikenali di dalam masyarakat Malaysia sebagai sifat suka menolong orang lain. Setiap anggota masyarakat sentiasa mengambil berat terhadap apa yang berlaku di sekitar mereka, peka terhadap apa yang berlaku kepada orang lain, menyayangi dan menghargai orang lain, membantu mereka yang teraniaya dan kurang bernasib baik serta merasa bertanggungjawab terhadap manusia lain."

(Siti Norlina Muhamad et al., 2004, hlm. 2)

Petikan tersebut menjelaskan sifat masyarakat Malaysia yang terdiri daripada masyarakat Melayu Islam yang kaya dengan nilai-nilai murni seperti penyayang, ringan tulang dan prihatin terhadap masyarakat sekeliling sekali gus menjadi lambang identiti bangsa. Rekaan kulit buku cerita kanak-kanak mengangkat nilai-nilai murni bangsa Melayu Islam yang terkenal dengan nilai kesopanan dan kasih sayang sebagai citra dan identiti bangsa yang perlu diteladani dan dipraktikkan oleh generasi muda. 


\section{KEAKRABAN MASYARAKAT DENGAN ALAM DALAM KULIT BUKU CERITA KANAK-KANAK}

Gambaran alam sekitar seperti hutan, haiwan dan sungai diperlihatkan dalam kulit buku cerita kanakkanak siri Young Aisyah dan Penulis Tunas Super yang menjadi identiti masyarakat Melayu yang rapat dengan alam. Salinah Jaafar (2017, hlm. 1) menyatakan bahawa unsur alam amat berkait rapat dengan dunia dan pemikiran masyarakat Melayu. Perlambangan alam seringkali digunakan untuk mengungkapkan pelbagai idea dan maksud tentang amalan, pegangan dan budaya kehidupan masyarakat Melayu. Hubungan manusia dengan alam merupakan salah satu kearifan tempatan yang diperlihatkan dalam kulit buku cerita kanak-kanak siri Young Aisyah dan Penulis Tunas Super.

Hampir kesemua rekaan kulit buku cerita kanak-kanak yang dianalisis memperlihatkan gambaran alam sekitar seperti haiwan, lautan dan hutan. Gambaran alam sekitar tersebut dilukis bersama-sama dengan watak kanak-kanak sekali gus memperlihatkan masyarakat Melayu yang dekat dengan alam. Salinah Jaafar (2017, hlm. 4) menjelaskan bahawa masyarakat Melayu melihat alam itu sebagai sesuatu yang amat rapat dengan jiwa dan hati nurani. Misalnya, kulit buku cerita kanak-kanak siri Young Aisyah: Rombongan Sekolah memperlihatkan seekor burung kakak tua sedang bertenggek di atas bahu kanak-kanak. Selain itu, lukisan kereta mainan yang dinaiki oleh kanak-kanak juga berbentuk zirafah. Gambaran tersebut dilukis dengan berlatar belakangkan kawasan hutan hijau. Contoh lain yang dapat dilihat, iaitu dalam kulit buku cerita kanak-kanak siri Young Aisyah: Cuti Sekolah yang memperlihatkan kanak-kanak berada di laut dengan gembira bersama-sama dengan kawan-kawan. Kanak-kanak turut digambarkan tersenyum gembira memegang seekor ikan. Secara tidak langsung rekaan kulit buku cerita kanak-kanak tersebut menjelaskan gambaran masyarakat Melayu yang akrab dengan alam sekitar. Hal ini dapat dilihat dalam petikan berikut:

"Budaya masyarakat Melayu yang menjadikan alam sebagai sumber pendidikan dan pembentukan sahsiah manusia telah wujud sejak dulu lagi. Masyarakat Melayu tradisional melihat alam sebagai sumber yang mengandungi pelbagai makna yang boleh dijadikan panduan, ajaran dan juga sebagai pembimbing dalam meneruskan kehidupan.” (Salinah Jaafar, 2017, hlm. 3)

Reka bentuk kulit buku yang memperlihatkan hubungan erat masyarakat Melayu dengan alam sejagat dapat dilihat dalam gambar rajah berikut:

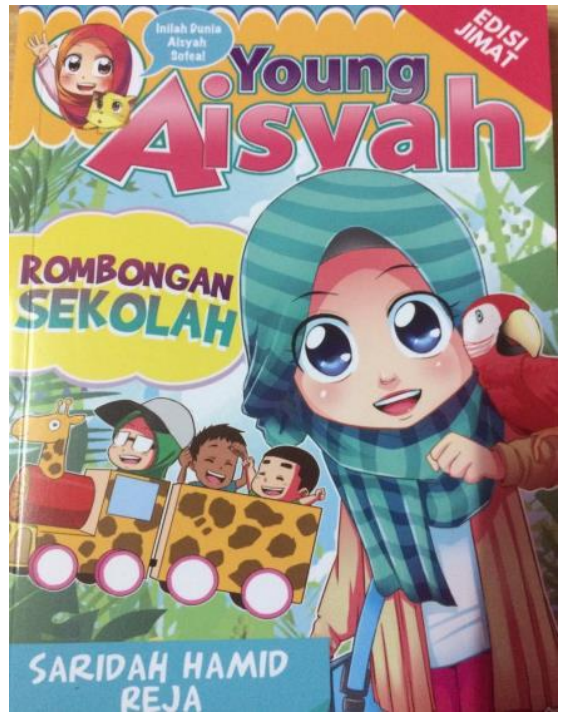

Gambar 5. Young Aisyah: Rombongan Sekolah (2019) 
Seterusnya, keakraban masyarakat Melayu dengan alam dapat dilihat dalam pemaparan lautan dalam kulit buku cerita kanak-kanak. Contohnya, dalam Young Aisyah: Cuti sekolah yang memaparkan imej lautan menjelaskan hubungan antara masyarakat Melayu dengan alam semesta yang menjadi ciri penting bangsa Melayu. Selain itu, laut juga digunakan sebagai jalan perhubungan dan menjadi sumber rezeki masyarakat Melayu pada zaman dahulu. Mohd Yusof Abdullah (2015) menjelaskan bahawa masyarakat Melayu tinggal di tepi laut, berjiwa dan berwatak pelaut dan bergantung hidup kepada laut. Hal ini menunjukkan hubungan erat antara masyarakat Melayu dengan laut. Ringkasnya, pemaparan imej alam seperti hutan, haiwan dan lautan dalam reka bentuk kulit buku cerita kanak-kanak menjelaskan citra bangsa Melayu yang menjalinkan hubungan erat dengan alam semesta.

\section{PEKERJAAN MASYARAKAT DALAM KLIT BUKU CERITA KANAK-KANAK}

Geertz (1973) menjelaskan kearifan tempatan merupakan unsur budaya tradisional yang berakar pada kehidupan masyarakat dan terkait dengan sumber daya manusia, sumber budaya, ekonomi, keamanan dan hukum. Geertz turut menyatakan bahawa kearifan tempatan tradisi berhubungan dengan kegiatan bertani, penternakan, pembangunan rumah dan pelbagai jenis sumber daya manusia sesebuah masyarakat.

Kearifan sesebuah bangsa dilihat melalui pekerjaan yang dilakukan dalam kehidupan. Berdasarkan kulit buku cerita kanak-kanak terpilih memperlihatkan pekerjaan sebagai nelayan ditonjolkan dalam rekaan kulit buku cerita kanak-kanak yang bertajuk Young Aisyah: cuti sekolah. Ilustrasi tersebut dapat dikaitkan dengan bangsa Melayu yang terkenal sebagai bangsa yang menetap di pesisir pantai dan bekerja sebagai nelayan. Laporan dalam Annual Report 1931 ada menyatakan bahawa masyarakat Melayu suka bekerja sendiri, menjadi petani dan juga nelayan. Hal ini dapat dilihat dalam petikan berikut:

"Few Malays are wage earners in the generally accepted sense of the term. They work well enough at their own time and in their own way but dislike employment to schedule and for the most part they devote themselves to the cultivations of their own plots of land or on the coast to fishing"

Reka bentuk kulit buku yang memperlihatkan pekerjaan yang menjadi identiti masyarakat Melayu, iaitu nelayan dapat dilihat dalam Gambar 6. 


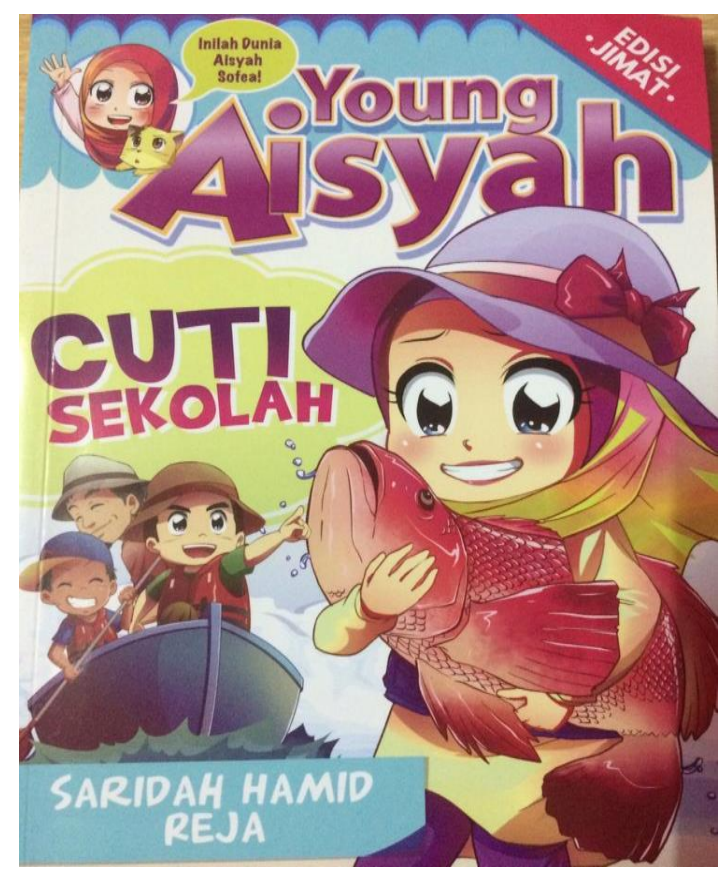

Gambar 6. Young Aisyah: Cuti Sekolah (2019)

Justeru, dalam pelukisan kulit buku cerita kanak-kanak yang menonjolkan kearifan tempatan salah satu unsur budaya tempatan yang diangkat oleh pelukis, iaitu pekerjaan yang dilakukan oleh masyarakat Melayu. Masyarakat Melayu terkenal sebagai masyarakat yang tinggal di pesisiran pantai dan pekerjaan utama mereka ialah sebagai nelayan. Hal ini secara tidak langsung memperlihatkan kemahiran masyarakat Melayu dalam ilmu pelayaran dan ilmu maritim yang merupakan lambang keagungan maritim Melayu. Hal ini dapat dilihat dalam petikan berikut:

"Masyarakat Melayu merupakan masyarakat yang berbudaya maritim, tinggal di tepi laut atau di tebing-tebing sungai. Mereka bergantung hidup kepada sungai dan laut."

(Mohd Yusof Abdullah, 2015, hlm. 1)

"Pusat-pusat perniagaan maritim di wilayah rumpun Melayu telah dikunjungi oleh pelbagai pedagang dan pengembara daripada China, India, Eropah, Arab, Farsi, India, Burma, Siam, dan lain-lain. Raja-raja dan pembesar rumpun Melayu merupakan pemodal dan usahawan yang gigih, manakala perwira, malim dan kelasi kapal mereka merupakan pelaut yang handal."

(Hashim Musa, Normahdiah Sheik Said, Rozita Che Rodi \& Siti Sarah Ab Karim, 2012, hlm.165)

Selain itu, masyarakat Melayu terkenal dengan kemahiran pembuatan perahu. Pembuatan perahu ini selari dengan pekerjaan mereka sebagai nelayan dan untuk meneroka tempat baru. Perahu merupakan pengangkutan yang digunakan oleh masyarakat dahulu kala untuk bergerak dari satu kawasan ke satu kawasan. Kemahiran pembuatan kapal dan masyarakat Melayu yang terkenal dengan masyarakat maritim dapat dilihat dalam Rozita Che Rodi \& Hashim Musa (2016, hlm.100):

"Kerajaan-kerajaan Melayu dalam sejarahnya pernah menggunakan jenis-jenis kapal besar tradisional Melayu, iaitu kapal jong, kapal ghali, kapal phinsi, kapal pinas dan kapal bedar yang digunakan untuk mengharungi lautan dalam menuju ke negara jauh di sebelah timur dan barat, kemahiran-kemahiran ini menggambarkan kebijaksanaan dan akal budi 
orang Melayu yang lahir daripada ekosistem masyarakat dan peradaban Melayu silam yang bersifat maritim."

Secara tidak langsung, rekaan kulit buku cerita kanak-kanak yang bertajuk Young Aisyah: Cuti Sekolah memperlihatkan pekerjaan masyarakat Melayu pada zaman dahulu sebagai nelayan. Selain itu, imej perahu juga menunjukkan kemahiran orang Melayu yang mahir dalam pembuatan perahu dan kapal. Ringkasnya, reka bentuk kulit buku cerita kanak-kanak tersebut menonjolkan kearifan tempatan masyarakat Melayu yang terkenal sebagai masyarakat maritim yang tinggal di pesisiran pantai serta mahir dalam pembuatan perahu.

\section{KESIMPULAN}

Kesimpulannya, rekaan kulit buku cerita kanak-kanak siri Young Aisyah dan Penulis Tunas Super yang diterbitkan oleh PTS Publishing House Sdn. Bhd. memperlihatkan ciri-ciri kearifan tempatan. Unsur seni dan kebudayaan, nilai-nilai murni, keperwiraan, kemahiran dalam pembuatan perahu dan keakraban dengan alam sekitar merupakan ciri-ciri kearifan tempatan yang menjadi identiti dan keagungan bangsa Melayu. Namun begitu, aspek kearifan tempatan yang diaplikasikan dalam kulit buku cerita kanak-kanak telah dimodenisasi bersesuaian dengan perubahan yang berlaku dalam persekitaran kanak-kanak dan kehendak kanak-kanak. Jelaslah, kulit buku cerita kanak-kanak bukan sekadar sebagai bahan komersial, namun turut menggalas peranan penting untuk mengangkat kearifan tempatan supaya tidak lapuk dek hujan, tidak lekang dek panas.

\section{PENGHARGAAN}

Ucapan penghargaan kepada pihak Akademi Pengajian Melayu, Universiti Malaya di atas geran Projek Penyelidikan RU Geran Fakulti Program - GPF003K-2018 - Nilai-nilai Tempatan Dalam Buku Kesusasteraan Kanak-kanak.

\section{RUJUKAN}

Alhafizh Mahardika. (2017). Penanaman karakter bangsa berbasis kearifan lokal di sekolah. Jurnal Pendidikan Kewarganegaraan. Vol. 7 (2), 16-27.

Annual Report on the Social and Economic Progress of the People of Straits Settlement for the Year 1931 dalam CO.573/577, hlm. 46.

Arba'ie Sujud, Nurul Azimah Abdull Sedik, Nik Rafidah Nik Muhamad Affendi \& Intan Zahariah Gaisun. (2014). Ekspresi emosi melalui bahan bacaan sastera kanak-kanak. Jurnal Melayu, 13, 72-84.

Ayu Nor Azilah Mohamad, Mohamed Ali Haniffa \& Wayu Nor Asikin Mohamad. (2017). Hang Tuah lambang peradaban Melayu. Jurnal Sultan Alauddin Sulaiman Shah, Special Issue, 20-34.

Badlihisham Mohd Nasir. (2012). Islam dan dakwah dalam zaman kebangkitan awal Islam dan era penjajahan Barat di Tanah Melayu. Islamiyyat, 34, 5-12.

Christine Suharto Cenadi. (1999). Elemen-elemen dalam desain komunikasi visual. Nirmana, Vol. 1 (1), 1-11.

Geertz, C. (1973). The interpretation of cultures: Selected essay. United States: Basic Books, Inc. Publishers.

Hadijah Rahmat. (2006). Peranan dan perkembangan sastera kanak-kanak. Kuala Lumpur: Dewan Bahasa dan Pustaka.

Hanafi Mohd Tahir, Normah Mustaffa \& Wan Amizah Wan Mahmud. (2018). Peranan visual reka bentuk kulit buku terhadap kemudahbacaan khalayak. Jurnal Komunikasi, 34 (4), 271-284.

Hanafi Mohd Tahir. (2016). Kemudahbacaan dan kebolehbacaan tipografi dan visual terhadap reka bentuk kulit buku. Dalam Muhamad Abdul Aziz AB Gani \& Andang Iskandar (Eds.), Jurnal Seni \& Budaya Malaysia. 
Indonesia (hlm. 58-63). Universiti Teknologi Mara Cawangan Perak, Malaysia: Fakulti Seni Lukis \& Seni Reka.

Hashim Musa, Normahdiah Sheik Said, Rozita Che Rodi \& Siti Sarah Ab Karim. (2012). Hati budi Melayu: Kajian keperibadian sosial melayu ke arah penjanaan Melayu gemilang. Gema Online ${ }^{\mathrm{TM}}$ Journal of Language Studies, Vol. 12(1), 163-182.

Hiwasaki, L., Luna, E., Syamsidik \& Marcal, J.A. (2014). Local and indigenous knowledge on climate-related hazards of coastal and small island communities in Southeast Asia. Climatic Change (2015), 128, 35-56.

Khaleda Irdina Batrisya. (2017). Puteri Berlian. Selangor: PTS Publishing House Sdn. Bhd.

Lawrence Dino. (2007). Pembangunan tarian tradisional zapin di Sarawak dalam memartabatkan seni tari Melayu Sarawak. Universiti Malaysia Sarawak, Sarawak.

Mohamed Anwar Omar Din. (2011). Asal-usul orang Melayu: Menulis semula sejarahnya. Jurnal Melayu, 7, 1-82.

Mohd Jirey Kumalah, Gusni Saat, Jabil Mapjabil, Rosazman Hussin, Teuku Afrizal \& Mustapa Abu Talip. (2015). Kearifan tempatan dan potensinya sebagai tarikan pelancongan berasaskan komuniti: Kajian kes komuniti Bajau Ubian di Pulau Mantanani, Sabah. Malaysian Journal of Society and Space, Vol. 11(12), 112-128.

Mohd Yusof Abdullah. (2015). Bicara dunia Melayu: Tradisi pelayaran Melayu. Kertas ini dibentangkan dalam Bicara Dunia Melayu, Tradisi Pelayaran Melayu di Jabatan Muzium Malaysia pada 29 Oktober 2015.

Norhayati Ab Rahman. (2014). Manifestasi kearifan masyarakat Melayu tradisional dalam karya sasterawan Fatimah Busu. Dalam Rahimah A. Hamid, (Ed.), Kearifan Tempatan: Pandainya Melayu dalam Karya Sastera (pp.139-153). Pulau Pinang, Malaysia: Penerbit Universiti Sains.

Nur Afiqah. (2016). P.A. Eksklusif. Selangor: PTS Publishing House Sdn. Bhd.

Nur Alia Irdina. (2017). Cik Diva Menari di London. Selangor: PTS Publishing House Sdn. Bhd.

Nur Nabihah. (2017). Persahabatan Dunia Ratu Berlian. Selangor: PTS Publishing House Sdn. Bhd.

Pengeran Mohd Pengeran Abd Rahman. (1992). Islam di Brunei Darusslam. Kuala Lumpur: Dewan Bahasa dan Pustaka.

Rasmawati (Ed.). (2017). Ayahku Superhero. Selangor: PTS Publishing House Sdn. Bhd.

Rasmawati (Ed.). (2016). Sukan. Selangor: PTS Publishing House Sdn. Bhd.

Reja. (2015). Young Aisyah: Hari Kantin. Selangor: PTS Publishing House Sdn. Bhd.

Rozita Che Rodi \& Hashim Musa. (2016). Tradisi maritim melayu yang hampir lenyap. Persidangan Antarabangsa Pengajian Alam Melayu 2016, 19-20 September 2016, Royal Asiatic Society, London. Anjuran Bersama Institut Alam dan Tamadun Melayu, ATMA, UKM, Dewan Bahasa dan Pustaka \& Department of South East Asia, SOAS, University of London.

Salinah Jaafar. (2017). Unsur alam dan masyarakat dalam teks terjemahan bahasa Melayu Surah Arrahman. Diakses pada 21 Jun 2020 dari https://umexpert.um.edu.my/file/publication/00001278_155188_66645.pdf.

Saridah Hamid \& Reja. (2019). Young Aisyah: Rombongan Sekolah. Selangor: PTS Publishing House Sdn. Bhd.

Saridah Hamid \& Reja. (2019). Young Aisyah: Juara Kampung Badak Berendam. Selangor: PTS Publishing House Sdn. Bhd.

Saridah Hamid \& Reja. (2019). Young Aisyah: Cuti Sekolah. Selangor: PTS Publishing House Sdn. Bhd.

Saridah Hamid \& Reja. (2019). Young Aisyah: Sayang Cikgu. Selangor: PTS Publishing House Sdn. Bhd.

Shaharuddin Pangilun \& Farhah Zaidar Mohamed Ramli. (2017). Penyebaran dan perkembangan islam di alam Melayu. Persidangan Antarabangsa Pengajian Islamiyyat Kali Ke-3 (IRSYAD2017). Diakses pada 21 Jun 2020 dari http://conference.kuis.edu.my/irsyad/images/eproceeding/2017/1015.pdf.

Siti Norlina Muhamad, Ahmad Kilani Mohamed, Zulkifli Haron \& Siti Aisyah Abdul Rahman. (2004). Budaya penyayang dalam kehidupan masyarakat Islam: Antara teori dan praktis. Diakses pada 21 Jun 2020 dari http://repo.uum.edu.my/1804/1/7.pdf.

Siti Haliza Yusop. (2017, September 28). Kerja rekaan kulit buku dipandang sebelah mata. Diakses pada 21 Jun 2020 dari https://www.bharian.com.my/rencana/sastera/2017/09/331281/kerja-rekaan-kulit-bukudipandang-sebelah-mata.

Smith, J. D. (2019). The important of cover design. Writers \& Artists: The Insider Guide to the Media. Diakses pada 21 Jun 2020 dari https://www.writersandartists.co.uk/self-publishing/articles/608/design-and-formatting.

Suraya Sintang, Khadijah Mohd Hambali @ Khambali. (2015). Budaya kenal-mengenal sebagai nilai kearifan tempatan di Sabah. Dalam Nazarudin Zainun (Ed.), Antropologi dan sejarah dalam kearifan tempatan (pp.94-100). Penerbit Universiti Sains Malaysia, Pulau Pinang.

The Center of Folklore Research, Faculty of Arts. (2007). Local wisdom protection fieldwork. Bangkok: Chulalongkorn University.

Wilson, R., Landoni, M. \& Gibb, F. (2014). Guidelines for designing electronic books. Diakses pada 21 Jun 2020 dari file:///C:/Users/Administrator/Downloads/Guidelines_for_Designing_Electronic_Books.pdf. 